\title{
Desempenho de codornas de corte EV1 alimentadas com diferentes níveis de lisina na dieta
}

[Performance of EVI meat type quail line fed different lysine level diets]

\author{
G.S.S. Corrêe $a^{1,5}$, M.A. Silva ${ }^{1,5}$, A.B. Corrêa ${ }^{2,5}$, D.O. Fontes ${ }^{1}$, G.G. Santos ${ }^{2,5}$, N.L. Dionello ${ }^{3}$, R.R. \\ Wenceslau $^{4}$, V.P.S. Felipe ${ }^{4}$, I.C. Ferreira ${ }^{2,5}$, J.E.R. Sousa ${ }^{2,5}$ \\ ${ }^{1}$ Escola de Veterinária - UFMG - Belo Horizonte, MG \\ Caixa Postal 567 \\ 30123-970 - Belo Horizonte, MG \\ ${ }^{2}$ Aluno de pós-graduação - EV-UFMG - Belo Horizonte, $\mathrm{MG}$ \\ ${ }^{3}$ Departamento de Zootecnia - FAEM-UFPel - Pelotas, RS \\ ${ }^{4}$ Aluno de graduação - EV-UFMG - Belo Horizonte, MG \\ ${ }^{5}$ Bolsista do CNPq
}

\begin{abstract}
RESUMO
Estudou-se a exigência de lisina total para a linha EV1 de codornas de corte na fase de crescimento utilizandose 288 aves, de ambos os sexos, em delineamento experimental inteiramente ao acaso, cujos tratamentos consistiram de dietas com seis níveis de lisina total, 1,$4 ; 1,5 ; 1,6 ; 1,7 ; 1,8$ e 1,9\%, e quatro repetições de 12 codornas por unidade experimental. Estudaram-se o ganho de peso $(\mathrm{g})$, o peso corporal ao final de cada período (g), o consumo alimentar ( $\mathrm{g}$ ) e a conversão alimentar ( $\mathrm{g}$ de alimento/g de peso) nos períodos inicial (do nascimento ao $21^{\circ}$ dia) e total (do nascimento ao $42^{\circ}$ dia de idade). No período inicial não se observou efeito do nível de lisina sobre o consumo alimentar, mas houve efeito quadrático sobre o peso corporal, ganho de peso e conversão alimentar, com máximo desempenho nos níveis de 1,$74 ; 1,75$ e $1,70 \%$ de lisina total, respectivamente. Para o período total houve efeito quadrático do nível de lisina da dieta sobre o peso no $42^{\circ}$ dia, ganho de peso, consumo e conversão alimentar, com máximo desempenho das codornas nos níveis de 1,$65 ; 1,65 ; 1,62$ e $1,64 \%$ de lisina total, respectivamente. A exigência de lisina total para ganho de peso de machos e fêmeas de codornas de corte do nascimento ao $21^{\circ}$ dia foi estimada em $1,75 \%$ e do nascimento ao $42^{\circ}$ dia, em $1,65 \%$ da dieta.
\end{abstract}

Palavras-chave: codorna, exigência nutricional, ganho de peso, consumo alimentar, conversão alimentar, lisina total

\begin{abstract}
Total lysine requirements for EV1 meat type quail line, during the growing phase were evaluated in a completely randomized experimental design with four level of lysine (1.4, 1.5, 1.6, 1.8, 1.9\%) and four replicates of 12 quails per experimental unit. The recorded traits were weight gain ( $g)$, body weight $(g)$, feed intake (g), feed:weight gain ratio $(\mathrm{g} / \mathrm{g}$ ) for the initial (from hatch to 21days of age) and total period (from hatch to 42 days of age). The effects of lysine level on body weight, weight gain and feed:weight gain ratio were quadratic and significant with maximum values estimated for 1.74, 1.75 and 1.70\% of total lysine respectively, but no effect on feed intake from hatch to 21 days of age was observed. Significant effects of lysine level on feed intake and feed: weight gain ratio from hatch to 42 days of age and on body at 42 days of age were observed, with maximum values estimated for 1.65, 1.65, 1.62, 1.64\% of total lysine in the diets. The total lysine requirements for weight gain (males and females) from hatch to 21 days of age were estimated in $1.75 \%$ and from hatch to 42 days of age in $1.65 \%$ of the diet.
\end{abstract}

Keywords: quail, nutritional requirement, weight gain, feed consumption, feed:weight gain ratio, total lysine, carcass yield

Recebido em 21 de dezembro de 2006

Aceito em 11 de outubro de 2007

E-mail: gerusacorrea@hotmail.com 


\section{INTRODUÇÃO}

Para a elaboração de programa nutricional para codornas de corte, o nutricionista baseia-se nas recomendações do NRC (Nutrient..., 1994) que são elaboradas para atender as exigências de codornas japonesas com peso corporal menor que o das codornas de corte. Essas exigências são baseadas em resultados de experimentos realizados há mais de 15 anos e em codornas com potencial genético diferente das criadas atualmente (Corrêa et al., 2007b).

A lisina é um dos aminoácidos de referências nos estudos nutricionais, não só por ser o segundo aminoácido limitante, depois da metionina, mas também porque é mais fácil de ser analisada que a metionina e, especialmente, que a cistina (Costa et al., 2001). Apresenta função exclusiva de deposição de proteína corporal e manutenção, não estando envolvida em outros processos metabólicos, além de já existirem informações sobre sua concentração e digestibilidade nos alimentos (Parksons e Backer, 1994). Também atua na síntese de carnitina, que age no transporte de ácidos graxos para a betaoxidação na mitocôndria (Barreto et al., 2006).

O excesso de aminoácidos presentes na corrente circulatória leva a seu catabolismo, já que estes não podem ser estocados no organismo animal. Como resultado dessa catabolização formam-se os carboidratos que são utilizados para cobrir as necessidades energéticas imediatas ou, então, são transformados em lipídios e estocados na forma de depósitos de gordura. Assim, aves que recebem dietas com excesso de aminoácidos ou proteínas podem apresentar maior quantidade de gordura corporal que aquelas alimentadas com níveis adequados. Além disso, a ingestão de elevada quantidade de proteína ou aminoácidos acarreta sobrecarga nos rins e no fígado, uma vez que o organismo necessita eliminar o excesso de nitrogênio ingerido (Garcia, 2006).

De acordo com o NRC (Nutrient..., 1994) a exigência de lisina total para codornas em crescimento é de 1,30\%. O INRA (Instituto..., 1999) propõe nível de $1,23 \%$ de lisina total do $21^{\circ}$ até o abate. Shrivastav e Panda (1999), ao utilizarem dietas com diferentes níveis de lisina para codornas de corte na fase de três a cinco semanas de idade, observaram melhores resultados de desempenho com dietas com 1,2\% de lisina total.

Shrivastav (2002) determinou exigências de 1,30 e $1,20 \%$ de lisina total para codornas européias do nascimento ao $21^{\circ}$ dia e do $22^{\circ}$ ao $35^{\circ}$ dia de idade, respectivamente. Barreto et al. (2006) estabeleceram a exigência de $0,9 \%$ de lisina total para machos de codornas européias do $21^{\circ}$ ao $49^{\circ}$ dia de idade, Corrêa et al. (2007a) estimaram a exigência de $1,62 \%$ de lisina total para codornas européias do nascimento ao $42^{\circ}$ dia de idade, e Wenceslau et al. (2007) verificaram melhor conversão alimentar quando codornas européias foram alimentadas com dietas com $1,66 \%$ de lisina total durante o período de crescimento.

Conforme citado por Fridrich et al. (2005), são escassas as pesquisas sobre exigências nutricionais e há, ainda, grande variação nos resultados encontrados pelos diversos autores.

Portanto, este trabalho teve como objetivo estudar o efeito de diferentes níveis de lisina total sobre o desempenho de codornas de corte, do grupo genético EV1, durante o período de crescimento.

\section{MATERIAL E MÉTODOS}

Foram utilizadas 288 codornas de corte EV1, de ambos os sexos, com um dia de idade, peso médio inicial de 8,0g, alojadas em baterias de arame galvanizado, equipadas com bebedouro e comedouro. O programa de luz adotado, durante a fase experimental, foi de 24 horas.

O delineamento experimental foi inteiramente ao acaso, com seis tratamentos (seis níveis de lisina total: 1,$4 ; 1,5 ; 1,6 ; 1,7 ; 1,8 ; 1,9 \%)$, e quatro repetições de 12 codornas por unidade experimental. Os níveis de lisina foram propostos segundo resultados encontrados por Corrêa et al. (2007d), os quais estimaram exigência de proteína bruta para máximo ganho de peso em codornas de corte em $30 \%$, o que corresponde ao nível de $1,65 \%$ de lisina total. O nível de $1,60 \%$, bem próximo de $1,65 \%$, serviu de base para formulação das dietas experimentais que continham 1,$4 ; 1,5 ; 1,6 ; 1,7 ; 1,8 ; 1,9 \%$ de lisina total. Assim, foram utilizados três níveis acima e dois abaixo da exigência estabelecida por Corrêa et al. (2007d). 
A dieta basal (Tab. 1) foi formulada para atender as exigências de proteína bruta, obtidas por Corrêa et al. (2007d) e o nível de metionina + cistina utilizado na formulação da dieta foi aquele estabelecido por Corrêa et al. (2005a) que observaram máximo ganho de peso para codornas de corte alimentadas com dietas que continham $0,93 \%$ de metionina + cistina. As demais dietas experimentais foram obtidas pela suplementação de L-lisina na dieta basal, em substituição ao amido de milho. Os demais aminoácidos foram suplementados na medida do necessário para manter constante a relação preconizada pelo NRC (Nutrient..., 1994), entre cada um dos aminoácidos: metionina (73\%), treonina $(78 \%)$, valina $(73 \%)$, isoleucina $(75 \%)$, arginina (96\%), fenilalanina $(74 \%)$ e 0 aminoácido lisina.

Tabela 1. Composições percentual e calculada das dietas experimentais usadas para codornas de corte EV1 na fase de crescimento, de acordo com os níveis de lisina das dietas

\begin{tabular}{|c|c|c|c|c|c|c|}
\hline \multirow[b]{2}{*}{ Ingrediente $(\%)$} & \multicolumn{6}{|c|}{ Nível de Lisina (\%) } \\
\hline & 1,40 & 1,50 & 1,60 & 1,70 & 1,80 & 1,90 \\
\hline Milho & 46,597 & 46,597 & 46,597 & 46,597 & 46,597 & 46,597 \\
\hline Farelo de soja & 46,133 & 46,133 & 46,133 & 46,133 & 46,133 & 46,133 \\
\hline Amido & 2,400 & 2,105 & 1,749 & 1,312 & 0,808 & 0,206 \\
\hline Óleo de soja & 1,728 & 1,728 & 1,728 & 1,728 & 1,728 & 1,728 \\
\hline Calcário & 1,052 & 1,052 & 1,052 & 1,052 & 1,052 & 1,052 \\
\hline Fosfato bicálcico & 0,945 & 0,945 & 0,945 & 0,945 & 0,945 & 0,945 \\
\hline Premix $^{1}$ & 0,500 & 0,500 & 0,500 & 0,500 & 0,500 & 0,500 \\
\hline Sal comum & 0,262 & 0,262 & 0,262 & 0,262 & 0,262 & 0,262 \\
\hline DL-metionina & 0,265 & 0,339 & 0,412 & 0,486 & 0,560 & 0,634 \\
\hline L-lisina & - & 0,127 & 0,255 & 0,383 & 0,510 & 0,638 \\
\hline L-Treonina & 0,117 & 0,196 & 0,275 & 0,354 & 0,434 & 0,513 \\
\hline L-Valina & - & - & - & 0,071 & 0,140 & 0,214 \\
\hline L-Isoleucina & - & 0,015 & 0,091 & 0,167 & 0,242 & 0,318 \\
\hline L-Arginina & - & - & - & - & 0,004 & 0,101 \\
\hline L-Fenilalanina & - & - & - & 0,009 & 0,084 & 0,158 \\
\hline \multicolumn{7}{|l|}{ Composição calculada } \\
\hline Proteína bruta (\%) & 25,29 & 25,29 & 25,29 & 25,29 & 25,29 & 25,29 \\
\hline Energia met. (kcal/kg) & 2,900 & 2,900 & 2,900 & 2,900 & 2,900 & 2,900 \\
\hline Cálcio $(\%)$ & 0,800 & 0,800 & 0,800 & 0,800 & 0,800 & 0,800 \\
\hline Fósforo disponível (\%) & 0,300 & 0,300 & 0,300 & 0,300 & 0,300 & 0,300 \\
\hline Sódio (\%) & 0,150 & 0,150 & 0,150 & 0,150 & 0,150 & 0,150 \\
\hline \multicolumn{7}{|l|}{ Aminoácido total } \\
\hline Lisina $(\%)$ & 1,400 & 1,500 & 1,600 & 1,700 & 1,800 & 1,900 \\
\hline $\begin{array}{l}\text { Metionina }+ \text { cistina } \\
(\%)\end{array}$ & 0,929 & 1,095 & 1,168 & 1,241 & 1,314 & 1,387 \\
\hline Triptofano (\%) & 0,328 & 0,328 & 0,328 & 0,328 & 0,328 & 0,328 \\
\hline Arginina (\%) & 1,724 & 1,724 & 1,724 & 1,724 & 1,728 & 1,824 \\
\hline Isoleucina $(\%)$ & 1,110 & 1,125 & 1,200 & 1,275 & 1,350 & 1,425 \\
\hline Valina $(\%)$ & 1,171 & 1,171 & 1,171 & 1,241 & 1,314 & 1,387 \\
\hline Fenilalanina $(\%)$ & 1,249 & 1,249 & 1,249 & 1,258 & 1,332 & 1,406 \\
\hline Treonina (\%) & 1,092 & 1,170 & 1,248 & 1,326 & 1,404 & 1,482 \\
\hline
\end{tabular}

${ }^{T}$ Composição por quilo: vit.A: $2.000 .000 U I ;$ vit $\mathrm{D}_{3}: 375.000 U I ;$ vit.E: $3.750 \mathrm{mg}$; vit. $\mathrm{K}_{3}: 500 \mathrm{mg}$; vit. $\mathrm{B}_{1}: 250 \mathrm{mg}$; vit. $\mathrm{B}_{2}$ : $750 \mathrm{mg}$; vit. $\mathrm{B}_{6}: 500 \mathrm{mg}$; vit $\mathrm{B}_{12}: 3.750 \mathrm{mcg}$; niacina: $6.250 \mathrm{mg}$; ac. pantotênico: $2.500 \mathrm{mg}$; biotina: $10 \mathrm{mg}$; ac. fólico: $125 \mathrm{mg}$; colina: $75.000 \mathrm{mg}$; selênio: $45 \mathrm{mg}$; iodo: $175 \mathrm{mg}$; ferro: $12.525 \mathrm{mg}$; cobre: $2.500 \mathrm{mg}$; manganês: $19.500 \mathrm{mg}$; zinco: $13.750 \mathrm{mg}$; avilamicina: $15.000 \mathrm{mg}$; narasin: $12.250 \mathrm{mg}$; BHT: $500 \mathrm{mg}$; vit.C: $12.500 \mathrm{mg}$.

O desempenho foi avaliado pelo ganho de peso $(\mathrm{g} /)$, peso ao final de cada período $(\mathrm{g})$, consumo de ração (g/ave) e conversão alimentar ( $g$ de dieta/g de peso) no período inicial (do nascimento ao $21^{\circ}$ dia) e período total (nascimento ao $42^{\circ}$ dia de idade). 
A análise dos dados foi realizada por meio do programa SAEG (Sistema..., 2004). As exigências de lisina foram obtidas regredindo-se as variáveis respostas em relação aos níveis de lisina em seus componentes lineares e quadráticos, para escolha do modelo de regressão que melhor descrevesse as observações.

\section{RESULTADOS E DISCUSSÃO}

Do nascimento ao $21^{\circ}$ dia de idade, houve efeito quadrático do nível de lisina total da dieta sobre o peso corporal, ganho de peso e conversão alimentar (Tab. 2), segundo as equações: $\hat{Y}_{i}=-158,57+340,92 \mathrm{X}_{\mathrm{i}}-97,85 \mathrm{X}_{i}^{2}$ (Fig. 1), $\hat{Y}_{i}=-159,93+331,23 \mathrm{X}_{\mathrm{i}}-94,78 \mathrm{X}_{i}^{2}$ (Fig. 2) e $\hat{Y}_{i}=11,75-11,57 \mathrm{X}_{\mathrm{i}}+3,41 \mathrm{X}_{i}^{2}$ (Fig. 3), com máximo desempenho das codornas nos níveis de lisina total de 1,$74 ; 1,75 ; 1,70 \%$, respectivamente.

O nível de $1,30 \%$ e de $1,23 \%$ de lisina total preconizado pelas tabelas de referências do NRC (Nutrient..., 1994) e INRA (Instituto..., 1999), respectivamente, para codornas em crescimento não atende às exigências do ganho de peso das codornas de corte. Isto se deve ao fato de as codornas de corte apresentarem taxa de deposição de massa muscular maior que codornas japonesas, que são utilizadas em experimentos para elaboração das tabelas de exigências nutricionais.

Hickling et al. (1990), ao compararem dietas com nível de lisina igual ou maior em 6, 12 e $18 \%$ que o nível recomendado pelo NRC (Nutrient..., 1984), verificaram que o ganho de peso de frangos até o $21^{\circ}$ dia decrescia com o aumento da concentração de lisina em relação ao nível recomendado pelo NRC.

Wenceslau et al. (2007), ao trabalharem com níveis de lisina total que variaram de 1,4 a 1,9\% para codornas européias durante o período inicial de crescimento, estimaram as exigências para ganho de peso e conversão alimentar em 1,66 e $1,59 \%$, respectivamente.

Não houve efeito significativo do nível de lisina total sobre o consumo alimentar das codornas (Tab. 2), à semelhança dos resultados observados por Colnago e Jensen (1992) e Conhalato (1998), para frangos de corte. Wenceslau et al. (2007) observaram efeito linear do nível de lisina sobre o consumo alimentar, com menor consumo para codornas alimentadas com $1,4 \%$ de lisina total durante o período inicial de crescimento (do nascimento ao $21^{\circ} \mathrm{dia}$ ).

Tabela 2. Peso no $21^{\circ}$ dia, ganho de peso, consumo de ração e conversão alimentar de codornas de corte EV1 do nascimento ao $21^{\circ}$ dia de idade, segundo o nível de lisina

\begin{tabular}{ccccc}
\hline $\begin{array}{c}\text { Nível de lisina } \\
(\%)\end{array}$ & $\begin{array}{c}\text { Peso no } 21^{\circ} \text { dia } \\
(\mathrm{g})\end{array}$ & $\begin{array}{c}\text { Ganho de peso } \\
(\mathrm{g})\end{array}$ & $\begin{array}{c}\text { Consumo de ração } \\
(\mathrm{g})\end{array}$ & $\begin{array}{c}\text { Conversão alimentar } \\
(\mathrm{g} / \mathrm{g})\end{array}$ \\
\hline 1,4 & 126,66 & 117,78 & 252,60 & 2,14 \\
1,5 & 133,23 & 124,27 & 270,75 & 2,18 \\
1,6 & 136,50 & 127,44 & 259,78 & 2,04 \\
1,7 & 137,02 & 128,08 & 237,33 & 1,85 \\
1,8 & 139,07 & 130,34 & 240,98 & 1,85 \\
1,9 & 135,66 & 126,94 & 273,63 & 2,15 \\
CV & 1,32 & 1,43 & 2,00 & 1,33 \\
Significância & $*$ & $*$ & ns & Nível de melhor \\
desempenho
\end{tabular}

$*=$ significativo $(\mathrm{P}<0,05) ; \mathrm{ns}=$ não significativo $(\mathrm{P}>0,05)$ pelo teste Fisher. 


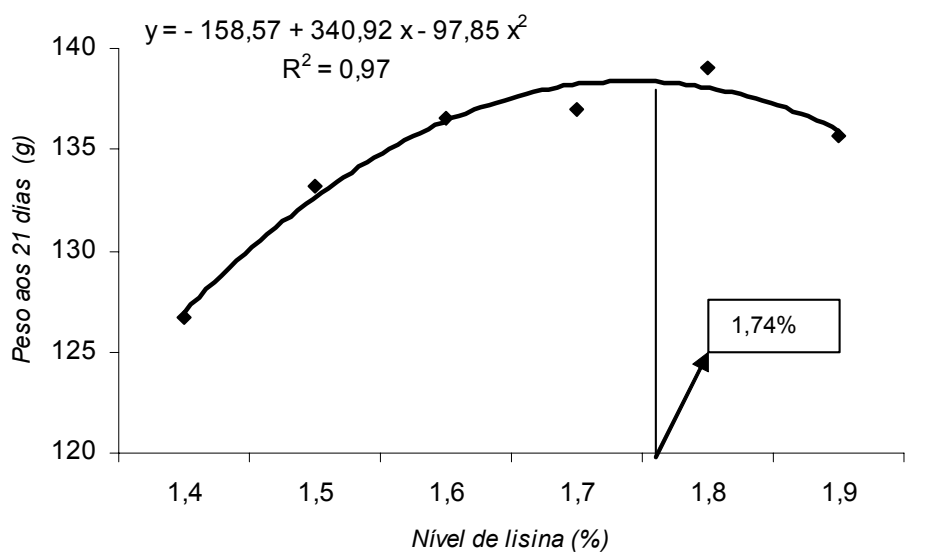

Figura 1. Regressão do peso no $21^{\circ}$ dia de idade de codornas de corte EV1 em relação ao nível de lisina da dieta.

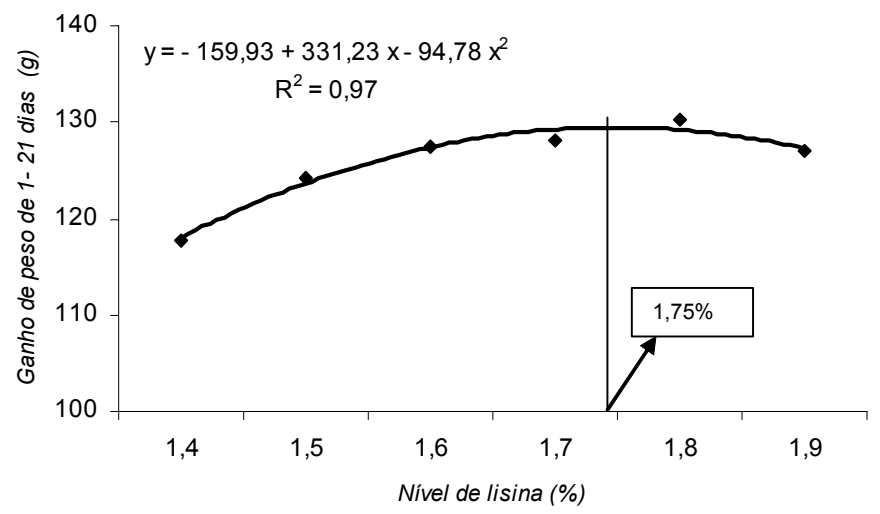

Figura 2. Regressão do ganho de peso do $1^{\circ}$ ao $21^{\circ}$ dia de idade de codornas de corte EV1 em relação ao nível de lisina da dieta.

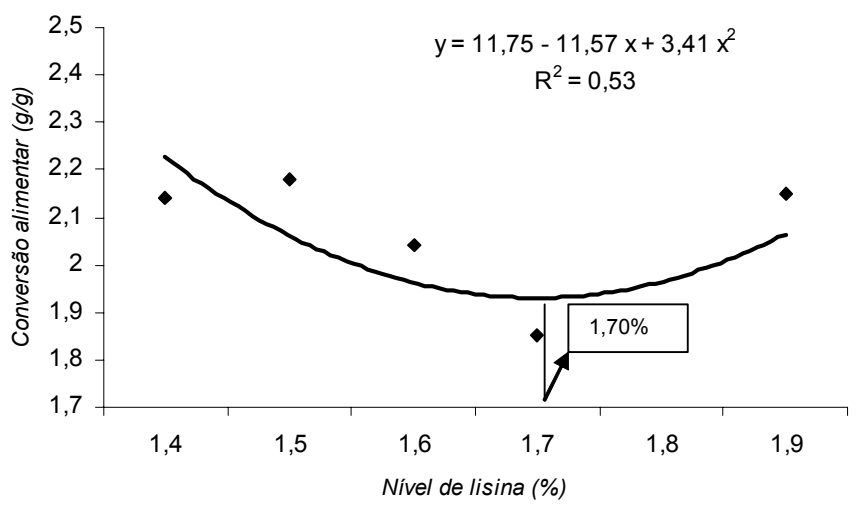

Figura 3. Regressão da conversão alimentar do $1^{\circ}$ ao $21^{\circ}$ dia de idade de codornas de corte EV1 em relação ao nível de lisina da dieta. 


\section{Corrêa et al.}

A não significância do efeito no nível de lisina sobre o consumo alimentar, pelas codornas em crescimento, indica que o imbalanço aminoacídico, provocado pelo excesso de lisina na dieta, não foi suficiente para influenciar negativamente $o$ consumo. Portanto, do nascimento ao $21^{\circ}$ dia de idade, níveis de lisina maiores que os recomendados pelo NRC (Nutrient..., 1994) e pelo INRA (Instituto..., 1999) melhoram o desempenho das codornas de corte e demonstram que elas apresentam potencial genético maior que as codornas de postura, conforme citado por Corrêa et al. (2006).

$\mathrm{O}$ peso corporal, ganho de peso, consumo e conversão alimentar do nascimento ao $42^{\circ}$ dia de idade (Tab. 3) foram influenciados pelos níveis de lisina da dieta, segundo as equações $\hat{Y}_{i}=-144,04+476,44 X_{i}-144,66 X_{i}^{2}$ (Fig. 4), $\hat{Y}_{i}=-145,40+466,75 X_{i}-141,58 X_{i}^{2}$ (Fig. 5), $\hat{Y}_{i}=3203,24-2988,55 X_{i}+922,20 X_{i}^{2}$ (Fig. 6) e $\hat{Y}_{i}=19,21-19,57 X_{i}+6,00 X_{i}^{2}$ (Fig. 7), com máximo desempenho para 1,$65 ; 1,65 ; 1,62 ;$ e $1,63 \%$ de lisina total, respectivamente.

Conforme observado por Klasing (1994), o fornecimento de nível de aminoácido abaixo da exigência provoca deficiência de aminoácido no organismo, aumento no consumo alimentar na tentativa de suprir as necessidades diárias de aminoácidos e redução do ganho de peso. Da mesma forma, dietas com excesso de aminoácidos prejudicam o ganho de peso em função de gastos extras de energia necessários para catabolizar os aminoácidos em excesso.

Os resultados sugerem, ainda, que há diminuição no nível exigido de lisina para máximo desempenho das codornas de corte com o avanço da idade, o que está relacionado ao menor ganho de peso da fase final de criação comparado com o da fase inicial, à semelhança dos resultados obtidos por Corrêa et al. (2005a). Os resultados de peso corporal no $42^{\circ}$ dia de idade foram também semelhantes aos observados por Corrêa et al. (2005b e 2007c).

Graber et al. (1971) verificaram nível constante de exigência de aminoácidos com o avanço da idade e do peso dos frangos.

Barreto et al. (2006) estabeleceram em $0,9 \%$ a exigência dietética de lisina total para machos de codornas européias do $21^{\circ}$ ao $49^{\circ}$ dia de idade, e Corrêa et al. (2007), ao trabalharem com codornas de corte do nascimento ao $42^{\circ}$ dia de idade, estimaram exigências de lisina em 1,62 e 1,61\%, respectivamente, para ganho de peso e conversão alimentar, à semelhança dos resultados obtidos na presente pesquisa.

Tabela 3. Peso final, ganho de peso, consumo de ração e conversão alimentar de codornas de corte EV1 do nascimento ao $42^{\circ}$ dia de idade, segundo o nível de lisina

\begin{tabular}{|c|c|c|c|c|}
\hline Nível de lisina (\%) & Peso final (g) & Ganho de peso (g) & Consumo de ração (g) & $\begin{array}{l}\text { Conversão } \\
\text { alimentar }(g / g)\end{array}$ \\
\hline 1,4 & 239,30 & 230,42 & 811,94 & 3,52 \\
\hline 1,5 & 245,29 & 236,33 & 821,51 & 3,48 \\
\hline 1,6 & 248,20 & 239,13 & 785,43 & 3,29 \\
\hline 1,7 & 247,52 & 238,58 & 770,49 & 3,23 \\
\hline 1,8 & 244,77 & 236,04 & 807,20 & 3,42 \\
\hline 1,9 & 239,09 & 230,37 & 861,83 & 3,74 \\
\hline $\mathrm{CV}$ & 1,80 & 1,91 & 1,85 & 1,89 \\
\hline Significância & $*$ & $*$ & $*$ & $*$ \\
\hline & \multicolumn{3}{|c|}{ Equação de regressão } & $\begin{array}{c}\text { Nível de melhor } \\
\text { desempenho }\end{array}$ \\
\hline Peso aos 42 dias & \multicolumn{3}{|c|}{$\hat{Y}_{i}=-144,04+476,44 X_{i}-144,66 X_{i}^{2}\left(\mathrm{R}^{2}=0,99\right)$} & 1,65 \\
\hline Ganho de peso & \multicolumn{3}{|c|}{$\hat{Y}_{i}=-145,40+466,75 X_{i}-141,58 X_{i}^{2}\left(\mathrm{R}^{2}=0,99\right)$} & 1,65 \\
\hline Consumo alimentar & \multicolumn{3}{|c|}{$\hat{Y}_{i}=3203,24-2988,55 X_{i}+922,20 X_{i}^{2}\left(\mathrm{R}^{2}=0,74\right)$} & 1,62 \\
\hline Conversão alimentar & \multicolumn{3}{|c|}{$\hat{Y}_{i}=19,21-19,57 X_{i}+6,00 X_{i}^{2}\left(\mathrm{R}^{2}=0,87\right)$} & 1,63 \\
\hline
\end{tabular}

*=significativo $(\mathrm{P}<0,05)$; ns=não significativo $(\mathrm{P}<0,05)$ pelo teste Fisher 


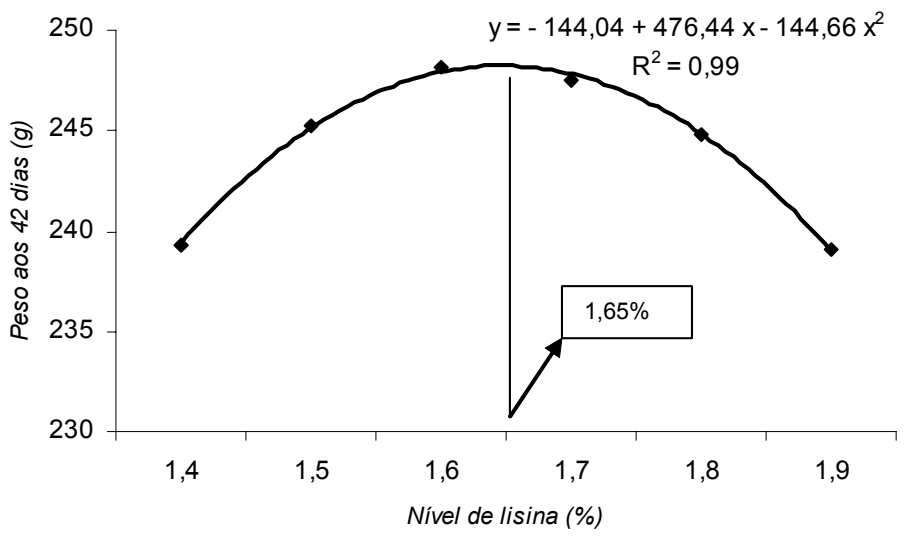

Figura 4. Regressão do peso médio no $42^{\circ}$ dia de idade de codornas de corte EV1 em relação ao nível de lisina da dieta.

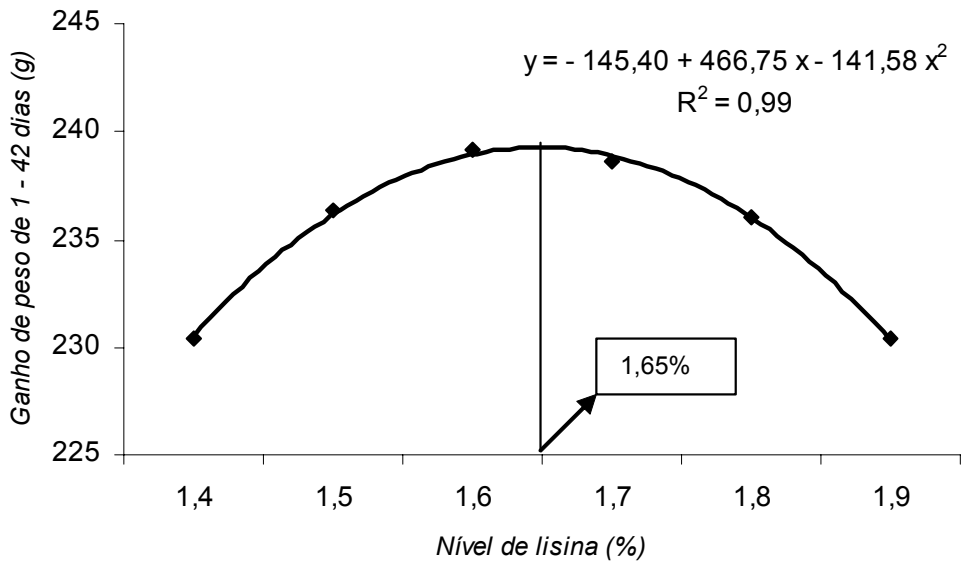

Figura 5. Regressão do ganho de peso do $1^{\circ}$ ao $42^{\circ}$ dia de idade de codornas de corte EV1 em relação ao nível de lisina da dieta.

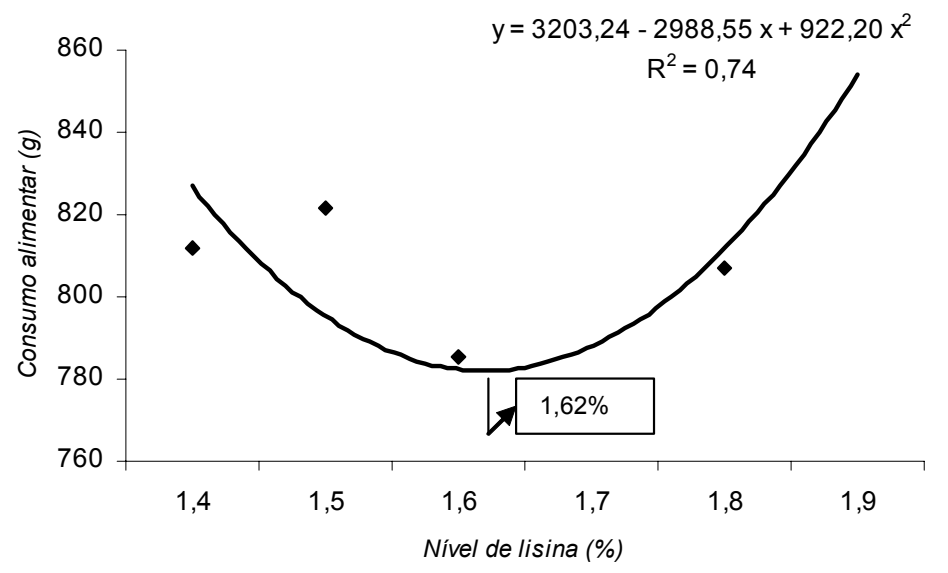

Figura 6. Regressão do consumo alimentar do $1^{\circ}$ ao $42^{\circ}$ dia de idade de codornas de corte EV1 em relação ao nível de lisina da dieta. 


\section{Corrêa et al.}

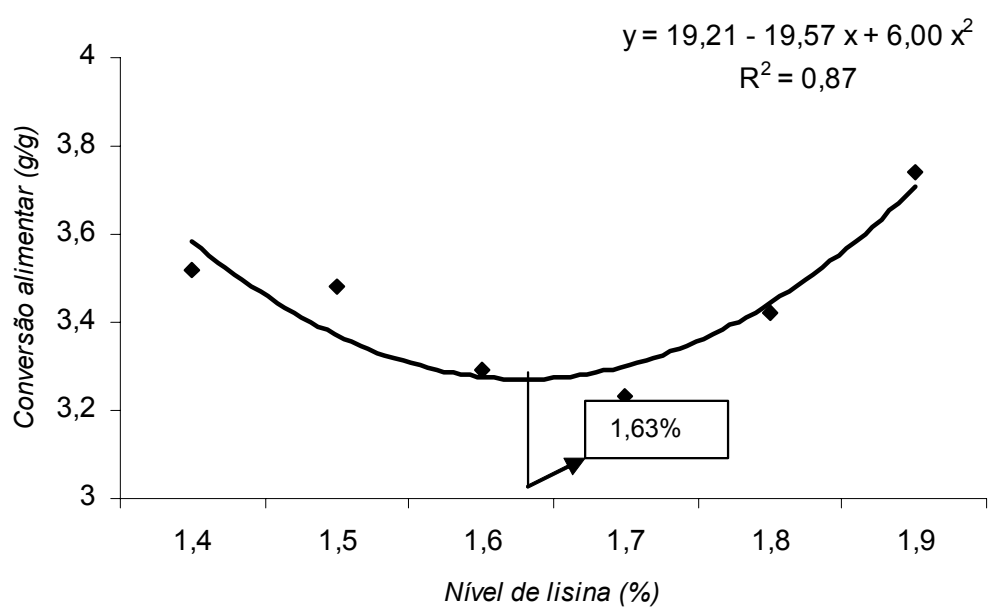

Figura 7. Regressão da conversão alimentar do $1^{\circ}$ ao $42^{\circ}$ dia de idade de codornas de corte EV1 em relação ao nível de lisina da dieta.

\section{CONCLUSÕES}

A exigência de lisina total para ganho de peso de machos e fêmeas de codornas de corte EV1 do $1^{\circ}$ ao $21^{\circ}$ dia de idade é estimada em $1,75 \%$ e do $1^{\circ}$ ao $42^{\circ}$ dia em $1,65 \%$ da dieta, o que corresponde aos consumos de lisina de 0,224g e $0,326 \mathrm{~g} / \mathrm{dia} /$ codorna, respectivamente.

\section{AGRADECIMENTO}

À FAPEMIG pelo financiamento do projeto e à AJINOMOTO pela doação dos aminoácidos.

\section{REFERÊNCIAS BIBLIOGRÁFICAS}

BARRETO, S.LT.; ARAÚJO, M.S.; UMIGI, R.T. et al. Exigência nutricional de lisina para codornas européias machos de 21 a 49 dias de idade. Rev. Bras. Zootec., v.35, p.750-753, 2006.

COLNAGO, G.L.; JENSEN, L.S. Putrescine effects on performance of male broiler chicks fed low-protein diets supplemented with essential amino acids. Poult. Sci., v.71, p.211-214, 1992.

CONHALATO, G. S. Exigência de lisina digestivel para frangos de corte machos, 1998. 79f. Dissertação (Mestrado) - Universidade Federal de Viçosa, Viçosa, MG.

CORRÊA, A.B.; CORRÊA, G.S.S.; SILVA, M.A. et al. Níveis de lisina da dieta e o desempenho de codornas de corte do nascimento aos 42 dias de idade. In: REUNIÃO ANUAL DA SOCIEDADE
BRASILEIRA DE ZOOTECNIA, 44., 2007, Jaboticabal. Anais..., Jaboticabal: SBZ, 2007a.

CORRÊA, G.S.S.; SILVA, M. A.; CORRÊA, A. B. et $a l$. Exigência de metionina + cistina para codornas de corte em crescimento. Arq. Bras. Med. Vet. Zootec., v.58, p.414-420, 2006.

CORRÊA, G.S.S.; SILVA, M.A.; CORRÊA, A.B. et al. Exigência de proteína bruta e energia metabolizável em codornas de corte durante a fase de crescimento. Arq. Bras. Med. Vet. Zootec., v.59, p.488-494, $2007 \mathrm{~b}$.

CORRÊA, G.S.S.; SILVA, M.A.; CORRÊA, A.B. et al. Exigência de proteína bruta e energia metabolizável para codornas de corte EV1. Arq. Bras. Med. Vet. Zootec., v.59, p.797-804, 2007c.

CORRÊA, G.S.S.; SILVA, M.A.; CORRÊA, A.B. et al. Exigência de proteína bruta para codornas de corte EV1 em crescimento. Arq. Bras. Med. Vet. Zootec., v.59, p.1278-1286, 2007d.

CORRÊA, G.S.S.; SILVA, M.A.; CORRÊA, A.B. et al. Níveis de metionina + cistina para híbridos EV1 de codornas européias no período de crescimento. In: REUNIÃO ANUAL DA SOCIEDADE BRASILEIRA DE ZOOTECNIA, 42., 2005, Goiânia. Anais..., Goiânia: SBZ, 2005a.

CORRÊA, G.S.S.; SILVA, M.A.; FONTES, D.O. et al. Efeito de diferentes níveis de proteína e energia sobre o rendimento de carcaça de codornas européias. Arq. Bras. Med. Vet. Zootec., v.57, p.266-271, 2005 b.

COSTA, E. G. P.; ROSTAGNO, H. S.; ALBINO, L. F. T. et al. Níveis de lisina digestível para frangos de corte machos na fase de 21 a 42 dias de idade. Rev. Bras. Zootec., v.30, p.1490-1497, 2001. 
FRIDRICH, A.B.; VALENTE, B.D.; SILVA, A.F. et al. Exigência de proteína bruta para codornas européias no período de crescimento. Arq. Bras. Med. Vet. Zootec., v.57, p.261-265, 2005.

GARCIA, E.A. Exigências nutricionais de codornas. In: II CONGRESSO LATINO-AMERICANO DE NUTRIÇÃO ANIMAL, 2., 2006, São Paulo. Anais..., São Paulo: CBNA-AMENA, 2006.

GRABER, G.; SCOTT, H.M.; BAKER, D.H. Sulfur amino acid nutrition of the growing chick: Effect of age on the dietary methionine requirement. Poult. Sci., v.50, p.851-858, 1971.

HICKLING, D.; GUENTER, W.; JACKSON, M.E. The effect of dietary methionine and lysine on broiler chicken performance and breast meat yield. Can. J. Anim. Sci., v.70, p.673-678, 1990.

INSTITUTO Nacional de Larecherche Agronomique. Alimentação dos animais domésticos: suínos, coelhos e aves. 2.ed. São Paulo: Roca, 1999. 245p.

KLASING, K.C. (Ed). Comparative avian nutrition. Wallingford: CAB International, 1994. p.350.

NUTRIENT requirements of poultry. 8.ed. Washington: National Academy of Sciences, 1984.
NUTRIENT requirements of poultry. 9.ed. Washington: National Academy of Sciences, 1994. p.44-45.

PARKSONS, C.M.; BAKER, D.H. The concept and usage of ideal proteins in the feeding of non ruminantes. In: SIMPÓSIO INTERNACIONAL DE PRODUÇÃO DE NÃO-RUMINANTES, 1994, Maringá. Anais... Maringá, 1994. p.119-128.

SHRIVASTAV, A.K.; PANDA, B.A review of quail nutrition research in Índia. World's Poult. Sci. J., v.55, p.73-81, 1999.

SHRIVASTAV, A.K. Recentes avanços na nutrição de codornas japonesas. In: SIMPÓSIO INTERNACIONAL DE COTURNICULTURA NOVOS CONCEITOS APLICADOS À PRODUÇÃO DE CODORNAS, 1., 2002, Lavras. Anais... Lavras: UFL, 2002. p.67-75.

SISTEMA de análises estatísticas e genéticas - SAEG. Versão 9.0. Viçosa: UFV, 2004.

WENCESLAU, R.R.; CORRÊA, G.S.S.; SILVA, M.A. et al. Exigência de lisina para características de desempenho em codornas de corte durante a fase inicial do período de crescimento. In: CONGRESSO INTERNACIONAL DE ZOOTECNIA, 9., 2007, Londrina. Anais... Londrina: UEL, 2007. p.1-4. 